\title{
Article \\ Screening for a Novel Gene, OsPSLSq6, Using QTL Analysis for Lodging Resistance in Rice
}

\author{
Dan-Dan Zhao ${ }^{1}$, Ju Hyeong Son ${ }^{1}$, Gang-Seob Lee ${ }^{2, *}$ and Kyung-Min Kim ${ }^{1, *(1)}$ \\ 1 Division of Plant Biosciences, School of Applied Biosciences, College of Agriculture and Life Science, \\ Kyungpook National University, Daegu 41566, Korea; qx288mm@naver.com (D.-D.Z.); \\ ff0319@hanmail.net (J.H.S.) \\ 2 Biosafety Division, National Academy of Agricultural Science, Rural Development Administration, \\ Jeonju 54874, Korea \\ * Correspondence: kangslee@korea.kr (G.-S.L.); kkm@knu.ac.kr (K.-M.K.)
}

Citation: Zhao, D.-D.; Son, J.H.; Lee, G.-S.; Kim, K.-M. Screening for a Novel Gene, OsPSLSq6, Using QTL Analysis for Lodging Resistance in Rice. Agronomy 2021, 11, 334. https://doi.org/10.3390/ agronomy11020334

Academic Editor: Najeeb Ullah Received: 30 December 2020 Accepted: 10 February 2021 Published: 13 February 2021

Publisher's Note: MDPI stays neutral with regard to jurisdictional claims in published maps and institutional affiliations.

Copyright: (c) 2021 by the authors. Licensee MDPI, Basel, Switzerland. This article is an open access article distributed under the terms and conditions of the Creative Commons Attribution (CC BY) license (https:// creativecommons.org/licenses/by/ $4.0 /)$.

\begin{abstract}
Lodging is the most common factor that affects crop productivity, reducing yield, grain quality, and harvesting efficiency of rice and other cereal crops. The Cheongcheong (Indica)/Nagdong (Japonica) doubled haploid (CNDH) genetic map was used to develop a lodging-resistant variety. The major agricultural traits of rice related to lodging resistance, such as the pushing strength of the lower stem before the heading date (PSLSB) at reproductive growth period and pushing strength of the lower stem after the heading date (PSLSA) at full ripe period were investigated. A quantitative trait locus (QTL) analysis of PSLSA and PSLSB detected on RM439-RM20318 on chromosome 6 has overlap in three consecutive years. RM439-RM20318 on chromosome 6 contained 15 lodging resistance candidate genes. Among the candidate genes, Os06g0623200, named OsPSLSq6, which is similar to Cinnamoyl-CoA reductase, involved lignin biosynthesis in defense responses. Lignin is the main structural component of vascular plants' secondary cell wall, which is not only related to plant growth and development but also to mechanical strength. OsPSLSq6 opens new possibilities to control lignin synthesis to improve lodging resistance. OsPSLSq6 can be used as a target gene for further studies to provide important information for the marker-assisted improvement of target traits and cloning genes underlying the QTL of interest.
\end{abstract}

Keywords: candidate genes; doubled haploid; lignin; lodging resistance; QTL; rice

\section{Introduction}

Lodging is one of the most common factors that affect crop productivity, reducing the yield, grain quality, harvesting efficiency, and drying costs of cereal and other crops, including corn, oats, tomato, rice, and wheat [1,2]. Lodging is referred to as height reduction due to the bending of the stem toward the ground. Lodging is considered a major constraint in crop productivity worldwide [3]. The contraction of conducting tissue and leaf shading causes a reduction in photo assimilation and photosynthesis, which in turn decreases the grain yield [1]. The factors that cause lodging in cereal crops include the increase in nitrogen levels, natural disasters (storms, typhoons, and flooding), soil density, disease, and seed type [4]. Lodging is most commonly mentioned as stem bending toward the ground, anchorage failure of the root, and stem breakage [4,5]. In general, lodging happens when the weight of the upper part of the plant increases and was disturbed by heavy rain, storms, and typhoons. Stem bending caused by increased panicle weight during the maturation process of rice directly affects the grain quality and yield [6,7]. Niu et al. [8] reported that heavy storms and rainfall are the major causes of reduced crop productivity in China and cause $73 \%$ of lodging. Lodging is highly frequent in the canopy of irrigated and deep-water rice grown under tropical conditions, leading to yield reduction of up to two tons per hectare [9]. One of the most common difficulties in developing high-yield varieties is lodging. Moreover, rice breeders have developed genes that could increase the grain 
yield in different rice cultivars; however, these cultivars developed more grains and larger panicles that the plants' culm cannot support, resulting in lodging [10]. Recently, breeding techniques with advances in genomics and biotechnology have increased the potential to transfer and identify lodging resistance genes to enhance the physical strength of stem and yield in rice crops [10]. The QTL analysis of lodging resistance and its related quantitative traits in rice has been reported [11-13]. Ookawa et al. [14] identified a culm strength QTL, named SCM2 (strong culm 2), which is similar in structure to the gene that controls panicle structure, APO1 (Aberrant panicle organization1). In addition, due to the pleiotropic SCM2, it can increase the number of spikelet and culm strength. In addition, the QTL analysis of lodging resistance in dry direct-seeded rice revealed id1001973-id1006772 on chromosome 1 , an important genomic region related to lodging resistance traits, and identified the target gene, gibberellic acid $3 \beta$-hydroxylase [15]. Kashiwagi and Ishimaru [1] reported a new locus, prl5, that can delay leaf senescence and increase the carbohydrates in the lower part of the stem to increase its lodging resistance. Kashiwagi et al. [16] identified the difference between the 10 rice cultivars and selected Nipponbare, which includes a stem diameter QTL ( $s d m 8)$, and Kasalath, which have four QTLs ( $s d m 1$, $s d m 7$, sdm8, and $s d m 12)$ of stem diameter from near-isogenic lines, and concluded that increasing the stem diameter can improve the lodging resistance of rice. Kong et al. [17] measured the hollow- and solidstemmed wheat cultivar; the detected lodging resistance with mechanical tissue width, low internodes weight, and stem walls width were highly significant. They also reported that multiple linear regression analysis showed that the mechanical tissue layer width is an important factor for variations in lodging resistance.

In recent years, with the adverse effect of climate change and the worsening typhoon, crop lodging has become increasingly serious. Therefore, it is particularly important to study the lodging resistance of rice. Developing new strategies became necessary, such as the measurement of the lower stem strength using the pushing strength of the lower stem in two different stages of development before the heading date (PSLSB) and 45 days after the heading date (PSLSA) to improve rice lodging resistance.

Therefore, this study used a doubled haploid population from a cross between a strong and resistant to lodging-type Indica variety "Cheongcheong" and a moderately difficult shattering japonica variety "Nagdong," by QTL analysis to further analyze the mechanism affecting crop lodging according to agronomic traits, such as PSLSB and PSLSA. Through QTL mapping, the candidate genes related to the pushing strength of the lower stem were identified, and among them, OsPSLSq6 that affects lignin biosynthesis was screened.

\section{Materials and Methods}

\subsection{Plant Materials and Field Experiment Design}

The current study used 120 Cheongcheong/Nagdong doubled haploid (CNDH) lines developed through crossing between the varieties, Cheongcheong (O. sativa L. ssp. indica) and Nagdong (O. sativa L. ssp. japonica) for experimental materials and QTL analysis of pushing strength of the lower stem. The genetic map was constructed by anther culture using an $F_{1}$ population derived from the cross between Cheongcheong and Nagdong [18]. The CNDH lines were cultivated on paddy filed in three consecutive years after developed in 2010 first $[19,20]$. The CNDH lines were used as a bridge parent for more than 10 years and as the transformation and gene expression validation group. The experiment was carried out for three consecutive years in the test field (Gunwi-gun, Gyeongbuk, Korea). Before sowing, the seeds were surface-sterilized with $25 \%$ prochloraz (Hankook Samgong, Seoul, Korea) and soaked in tap water for three days at $33^{\circ} \mathrm{C}$ in an incubator. On 23 April 2018, 25 April 2019, and 24 April 2020, the plants were transplanted in a randomized block design after 30 days of sowing. Cheongcheong, Nagdong, and the $120 \mathrm{CNDH}$ lines were transplanted at $15 \times 30 \mathrm{~cm}$ plant distance. Based on the standard cultivation methods of Rural Development Administration, $\mathrm{N}-\mathrm{P}_{2} \mathrm{O}_{5}-\mathrm{K}_{2} \mathrm{O}$ at $9-4.5-5.7 \mathrm{~kg} / 10$ ha was used as a fertilizer [21]. 


\subsection{Phenotype Evaluation}

The major agricultural traits related to lodging in rice, such as PSLSA and PSLSB, were investigated. PSLSB was measured each year 85 days after sowing, and PSLSA was measured after 45 days of the heading date for each cultivar. The pushing strength of the lower stem was measured using a digital force gauge (Imada, Japan) and 12-inch rafter square table (MAYA-300, China). The digital force gauge was set perpendicularly at $20 \mathrm{~cm}$ of the plant from the ground by pushing the plants to a $45^{\circ}$-angle from the vertical direction [1], and the 12-inch rafter square tables were used for the comparison of angles and heights (Supplementary Figure S1). PSLSA and PSLSB of four randomly chosen plants for each line were measured and then averaged for analysis. The yield component analysis was based on the formula $\mathrm{Y}=\mathrm{N} \times \mathrm{W} \times \mathrm{F} \times 10^{-5}\{\mathrm{Y}=$ grain yield ( $\mathrm{t} / \mathrm{ha}), \mathrm{N}=$ spikelet number $/ \mathrm{m}^{2}, \mathrm{~W}=1000-\mathrm{g}$ weight $(\mathrm{g})$, and $\mathrm{F}=$ filled spikelet $\}$ [22].

\subsection{QTL Analysis for PSLSA and PSLSB}

The CNDH line genetic maps used 788 SSR markers. Based on Cheongcheong and Nagdong polymorphism analysis, 423 SSR markers showed polymorphism, and among those, we selected 222 SSR markers, which represent codominant genes in PCR amplification in both Cheongcheong and Nagdong. The CNDH line genetic map total length was $2121.7 \mathrm{cM}$, the mean distance between the markers used to generate the genetic map was $10.6 \mathrm{cM}$, and these markers were evenly distributed across all 12 chromosomes of rice by Mapmaker version $3.0[19,23,24]$. The naming of the QTLs was based on the nomenclature proposed previously by McCough and Doerge [25]. The Windows QTL cartographer 2.5 [26] was used for the analysis of QTLs related to the pushing strength of the lower stem. Windows QTL cartographer program, Version 2.5, requires several factors, such as the labels of all markers, the positions of the genetic distance between each marker, genotyping data, chromosome numbers, and target trait values. Furthermore, in the Kosambi function for the value of $120 \mathrm{CNDH}$ lines, the composite interval mapping of the entire genome was operated, and a threshold LOD 3.0 was used in all required data.

\subsection{Gene Information Analysis and Statistical Analysis}

The deficiency of QTL analysis can be overcome by the discovery of candidate genes, and further QTL analysis can be carried out based on candidate gene group analysis. To create a physical map, we used RAP-DB [27] and RiceXpro [28] for the annotation of candidate genes, and ORFs (open reading frames) were found among SSR markers and classified based on their function related to lodging. NCBI [29] and BioEdit 7.0 [30] were used for homologous multiple sequence comparison. For the analysis of the protein and protein interaction association network, the STRING (https://string-db.org/ accessed on 27 December 2020) database was used. Statistical evaluations of the obtained data were done using GraphPad Prism (Version 6.07) and SPSS program (Version 25).

\section{Results}

\subsection{Phenotypic Evaluation and Comparison to Agricultural Characteristics}

The plant phenotypes of $120 \mathrm{CNDH}$ lines, including PSLSA, PSLSB, and yield were observed (Supplementary Table S1). Based on the three-year data, the PSLSA and PSLSB in Cheongcheong were higher than in Nagdong. The yield in Cheongcheong was higher than in Nagdong for three consecutive years. In addition, the CNDH line showed similar frequency distribution curves to the normal distribution, which revealed that all examined agricultural traits were quantitative traits, and one or more genes controlled the quantitative traits (Figure 1) [31]. The correlation analysis between PSLSA and yield shows highly significant correlation in each year. PSLSB shows significantly strong correlation with yield in 2019 and 2020, but not in 2018 (Table 1). All traits shown are quantitative, which are greatly influenced by the environment [32]. 

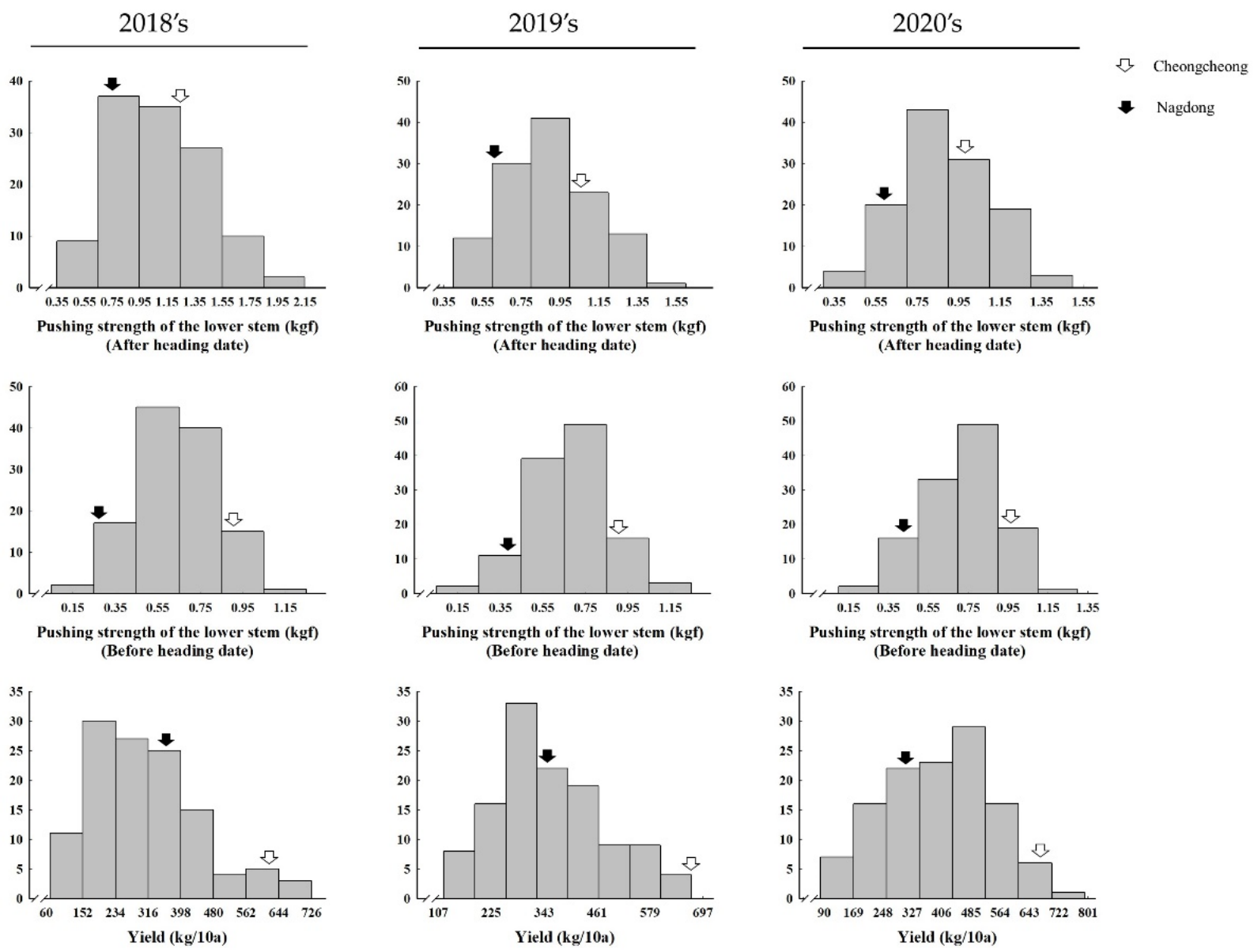

Figure 1. Frequency distribution of pushing strength of the lower stem after the heading date (PSLSA), pushing strength of the lower stem before the heading date (PSLSB), and yield in the CNDH population. The hollow white arrow represents Cheongcheong, and the solid black arrow represents Nagdong.

Table 1. Analysis of the correlation between PSLSA, PSLSB, and yield in the CNDH population.

\begin{tabular}{lllll}
\hline Year & Trait & PSLSA (kgf) & PSLSB (kgf) & Yield (kg/10a) \\
\hline \multirow{2}{*}{2018} & PSLSA & 1.000 & & \\
& PSLSB & $0.261^{* *}$ & 1.000 & 1.000 \\
& Yield & $0.425^{* *}$ & 0.103 & \\
& PSLSA & $1.000^{* *}$ & & 1.000 \\
& PSLSB & $0.530^{* *}$ & 1.000 & \\
& Yield & $0.544^{* *}$ & $0.297^{* *}$ & 1.000 \\
& PSLSA & $1.000^{* *}$ & & 1.000 \\
& PSLSB & $0.643^{* *}$ & $0.423^{* *}$ &
\end{tabular}

** Correlation is significant at the 0.01 level. PSLSA: Pushing strength of the lower stem after the heading date PSLSB: Pushing strength of the lower stem before the heading date.

\subsection{QTL Analysis Associated with PSLSA and PSLSB}

PSLSA and PSLSB were detected using QTL analysis (Figure 2). Based on the threeyear data, we detected one QTL on chromosomes 1, 7, and 8. On chromosome 5, 6, and 9, four, six, and two QTLs were detected, respectively. Among them, RM5311-RM4691 of chromosome 5 was a region related to PSLSB detected for three years. The highest LOD score was 5.23, which was detected in locus qPSLSA5; the phenotypic variation was $32 \%$, derived from the allele of Cheongcheong. RM24288-RM1896 of chromosome 9 is a region related to PSLSB detected in 2019 and 2020, the higher LOD score was 4.40, which was detected in locus qPSLSB9, the allele derived from Cheongcheong with $35 \%$ phenotypic 
variation. RM439-RM20318 of chromosome 6 is a region related to both PSLSA and PSLSB detected for three years. All alleles derived from Cheongcheong had the highest LOD score of 4.43, which was detected in locus qPSLSB6-3 with 30\% phenotypic variation (Supplementary Table S2).

Chr. 1

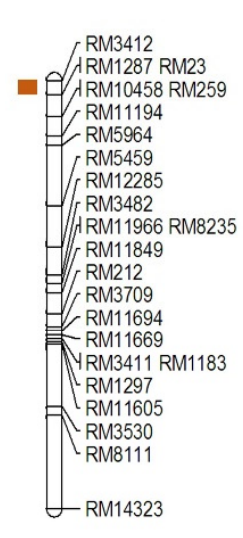

2018 PSLSA

2019 PSLSA

2020 PSLSA
Chr. 5

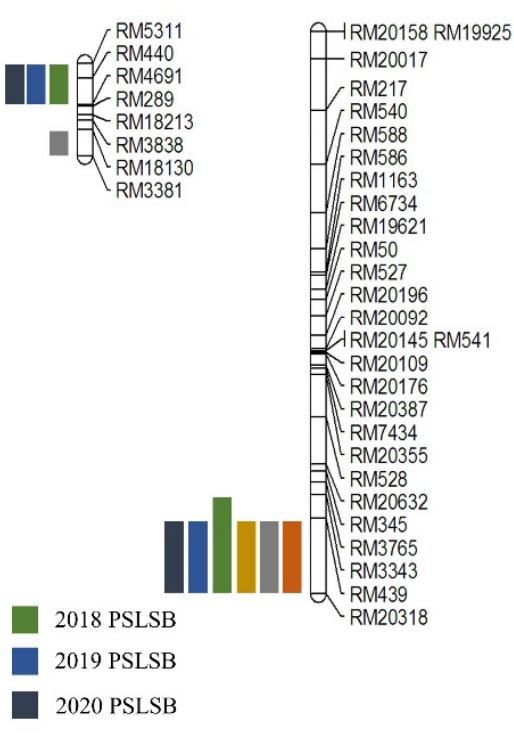

Chr. 7

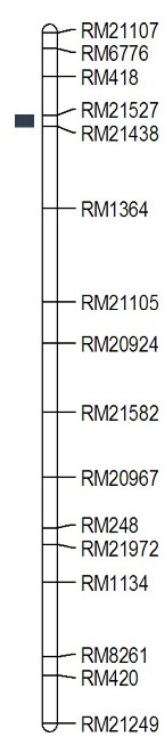

Chr. 8

Chr. 9

Figure 2. The chromosomal location of QTL associated with PSLSA and PSLSB in the CNDH population. The PSLSA and PSLSB QTLs mapped in RM439-RM20318 on chromosome 6 have overlapped for three consecutive years.

\subsection{Search Candidate Genes Associated with PSLSA and PSLSB}

QTL analysis for PSLSA and PSLSB detected six QTLs on chromosome 6 over three years. These QTLs had overlapped location in RM439-RM20318 on chromosome 6. The interval markers RM439-RM20318 of all ORFs were screened by NCBI, and there were 15 ORFs related to the pushing strength of the lower stem. Fifteen ORFs were classified according to their function [33] (Table 2). Eleven candidate genes were found to be involved in cell function, and four candidate genes were associated with abiotic stress. The candidate gene involved in abiotic stress includes genes similar to thioredoxin peroxidase, phytosulfokines 1 precursor, amino acid/polyamine transporter II family protein, and genes similar to EF-hand $\mathrm{Ca}^{2+}$-binding protein CCD1. The candidate genes involved in cell function consisted of ribose-phosphate pyrophosphokinase 2, SBP domain-containing protein, polyubiquitin, glycosyl transferase, family 43 protein, and those similar to Alpha-expansin OsEXPA16, Cinnamoyl-CoA reductase, 4-coumarate-CoA ligase 1, ANT (Ovule development protein aintegumenta), auxin efflux carrier protein, FtsH protease (VAR2) (Zinc-dependent protease), and GRAB2 protein. Among the candidate genes, Os06g0623200, named OsPSLSq6, which is similar to Cinnamoyl-CoA reductase, involved lignin biosynthesis for defense responses, was selected as the preferred gene in this study (Figure 3). Lignin is the main structural component of vascular plants' secondary cell wall, which is related not only to plant growth and development but also to mechanical strength. 
Table 2. Fifteen related genes screened from the target interval RM439-RM20318 on chromosome 6.

\begin{tabular}{ll}
\hline Gene & No. of Genes \\
\hline Cell function & 11 \\
Ribose-phosphate pyrophosphokinase 2 & \\
Similar to Alpha-expansin OsEXPA16 & \\
Similar to Cinnamoyl-CoA reductase & \\
Similar to 4-coumarate-CoA ligase 1 & \\
Similar to ANT (Ovule development protein aintegumenta) & \\
Similar to Auxin efflux carrier protein & \\
SBP domain-containing protein & \\
Similar to FtsH protease (VAR2) (Zinc-dependent protease) & \\
Similar to GRAB2 protein & \\
Polyubiquitin & \\
Glycosyl transferase, family 43 protein & \\
Abiotic stress & \\
Similar to Thioredoxin peroxidase & \\
Phytosulfokines 1 precursor & \\
Amino acid/polyamine transporter II family protein & \\
Similar to EF-hand Ca2+-binding protein CCD1 & \\
\hline
\end{tabular}

\subsection{Phylogenetic Tree Analysis and Homology Sequence}

QTL analysis for PSLSA and PSLSB in 120 CNDH lines detected RM439-RM20318 on chromosome 6 and found a candidate gene, OsPSLSq6, associated with lignin biosynthesis, which is similar to Cinnamoyl-CoA reductase. Furthermore, the results of BLAST analysis through NCBI showed that OsPSLSq6 had a very similar sequence to the Cinnamoyl-CoA reductase 2 of Oryza sativa L., Oryza brachyantha, and Aegilops tauschii, and to CinnamoylCoA reductase 1 of Setaria viridis, Sorghum bicolor and Zea mays. The phylogenetic tree analysis was confirmed the genetic similarity between the OsPSLSq6 of Oryza sativa L., Oryza brachyantha, Setaria viridis, Sorghum bicolor, Zea mays, and Aegilops tauschii. In addition, to predict the functional partners using the domain of OsPSLSq6, we found that OsPSLSq6 interact with 10 different proteins (cinnamate-4-hydroxylase, hydroxycinnamoyl-transferase 1, hydroxycinnamoyl-transferase 2, 4-coumarate-CoA ligase, cytosolic aldehyde dehydrogenase RF2D, caffeoyl-CoA O-methyltransferase, caffeoyl-CoA O-methyltransferase 1, Putative Expresses, ferulate-5-hydroxylase, and aldehyde dehydrogenase) (Figure 4).

In particular, based on the three consecutive years of data investigation and analysis, it is observed that CNDH-5, CNDH-11, and CNDH-45 exhibited the pushing strength of the lower stem susceptible among the $120 \mathrm{CNDH}$ lines, and CNDH-67, CNDH-79, and CNDH82 were resistant to the pushing strength of the lower stem (Figure 5). Among them, Cheongcheong, Nagdong, CNDH-5, CNDH-67, CNDH-79, and CNDH-82 PSLSA scores were all higher than the PSLSB score, except CNDH-11 and CNDH-45. The results support that the stem has a different mechanical strength at different growth stages and further indicate the importance of measuring the stem mechanical strength at two different growth stages (before heading date and 45 days after the heading date). 

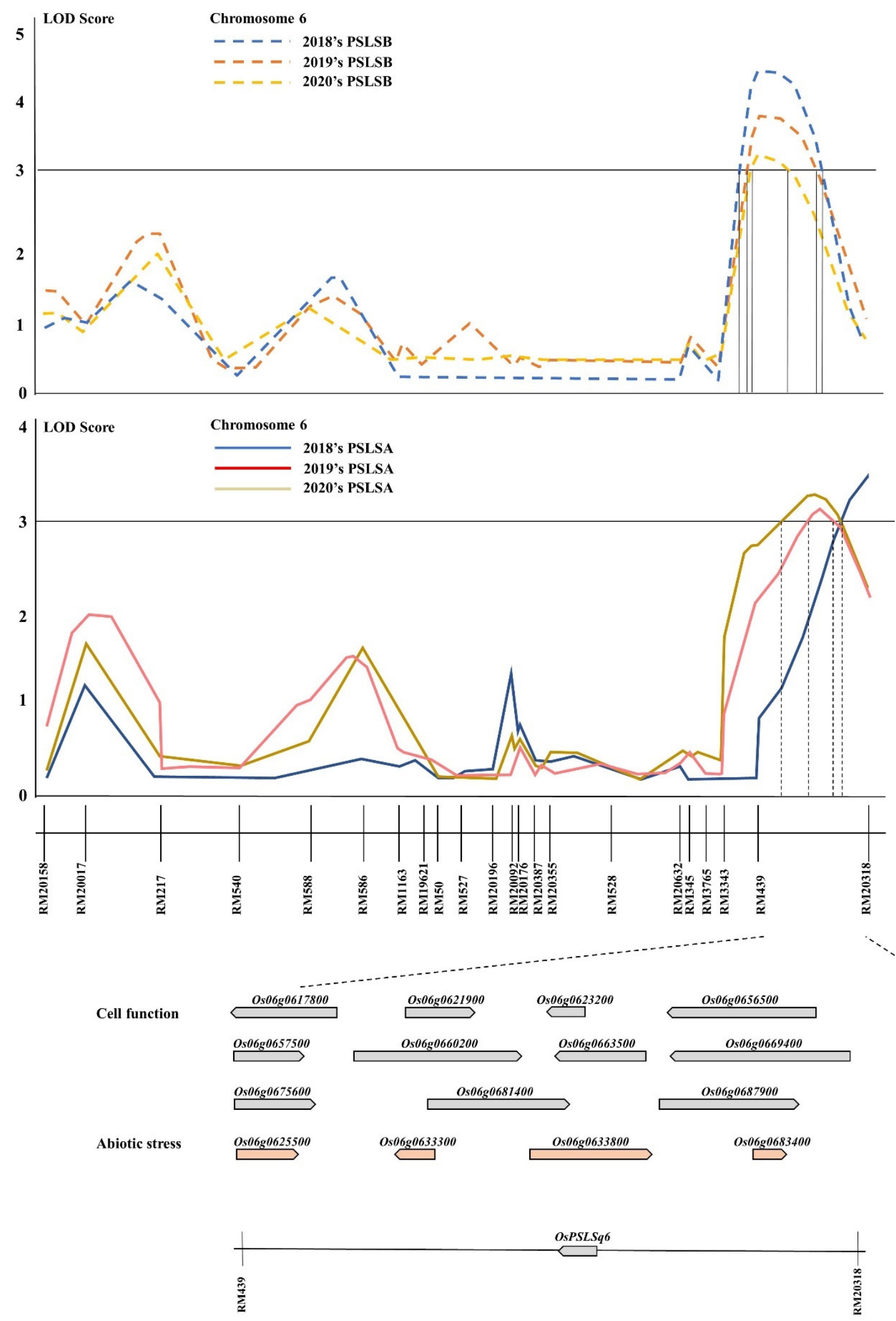

Figure 3. QTL analysis and physical mapping of the gene related to the pushing strength of the lower stem. In the region of the target area from RM439 to RM20318 on chromosome 6, several candidate genes were found. Among which, OsPSLSq6 was screened as a lodging resistance gene. 
(a)

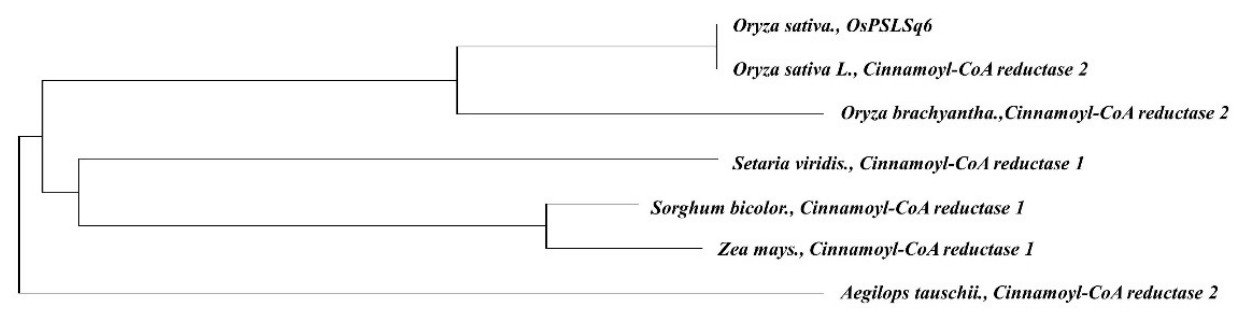

(b)

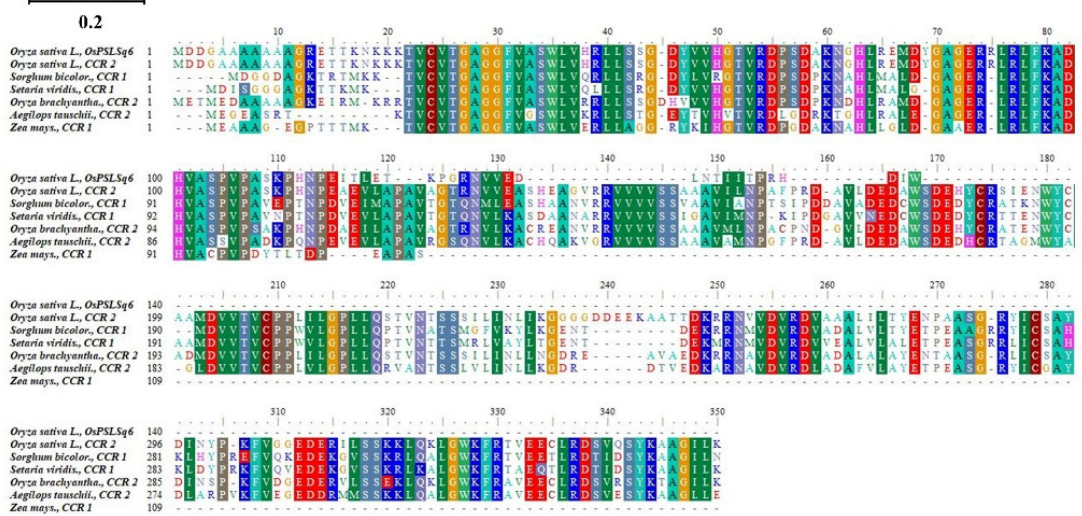

(C)

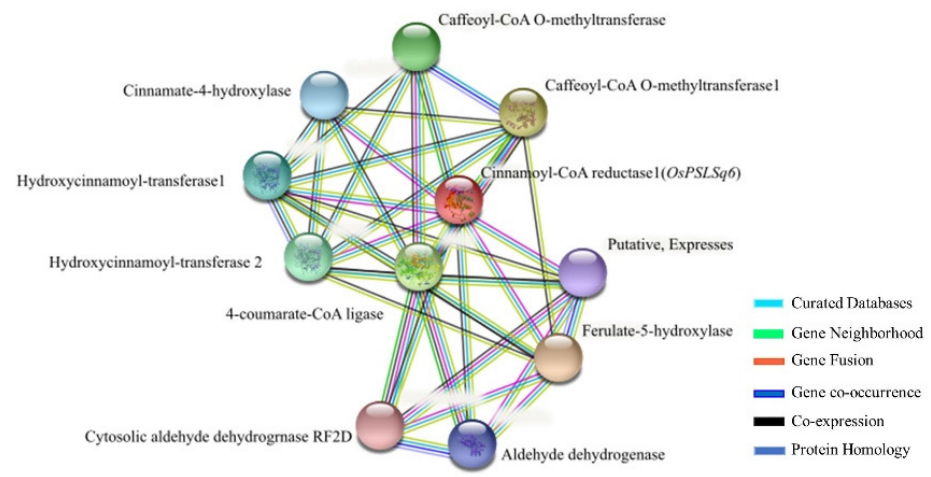

Figure 4. Sequence analysis of OsPSLSq6. (a) The phylogenetic tree was used to analyze the gene and homology gene. The phylogenetic tree was constructed using the parsimony method with 1000 bootstrap replicates; (b) as a result of comparing the protein sequences of the homologous genes of OsPSLSq6, a very high similarity was observed in Oryza. sativa L., Oryza brachyantha, Setaria viridis, Sorghum bicolor, Zea mays, and Aegilops tauschii; (c) protein interaction of OsPSLSq6. OsPSLSq6 interacts with cinnamate-4-hydroxylase, hydroxycinnamoyl-transferase 1, hydroxycinnamoyl-transferase 2, 4-coumarate-CoA ligase, cytosolic aldehyde dehydrogenase RF2D, caffeoyl-CoA O-methyltransferase, caffeoyl-CoA O-methyltransferase 1, putative expresses, ferulate-5-hydroxylase, and aldehyde dehydrogenase.

2018's

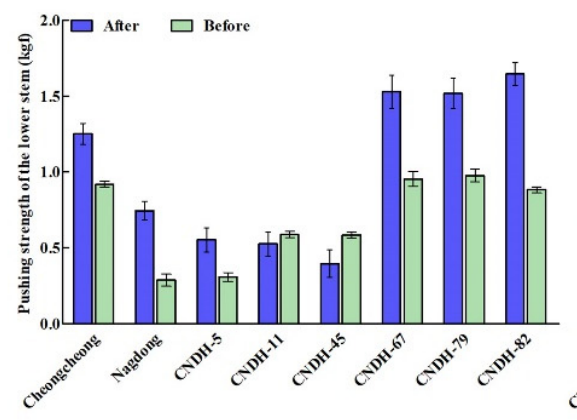

2019's

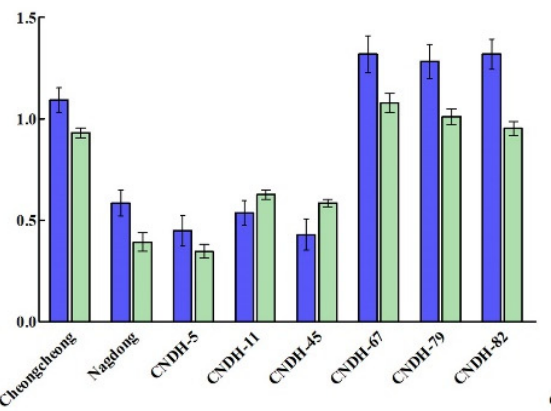

2020's

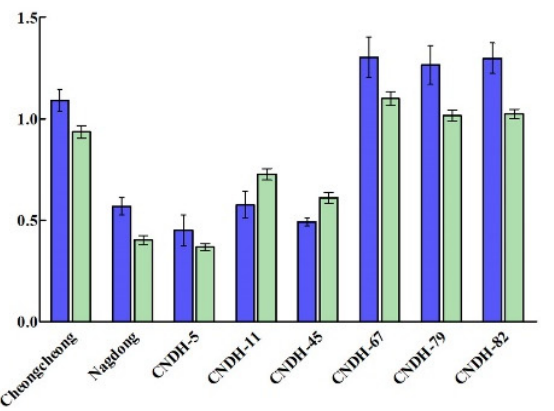

Figure 5. Comparison of susceptible and resistance lines for pushing strength of the lower stem. Pushing strength of the lower stem susceptible line; Nagdong, CNDH-5, CNDH-11, and CNDH-45; Pushing strength of the lower stem resistance line; Cheongcheong, CNDH-67, CNDH-79, and CNDH-82. 


\section{Discussion}

Lodging is one of the most common problems in cereal crops, affecting crop growth, development, and yield. Lodging is the increase in panicle weight caused by strong winds and heavy rain; when a plant's stem is too weak to support the panicle weight, it causes them to fall to the ground. Lodging is a usual problem in many crops, such as barley, oats, tobacco, corn, wheat, and rice [34-37]. Moreover, lodging can affect the production quality, decreasing the harvesting efficiency and crop yield [38]. By observing the effect of lodging on grain quality and yield, it was found that the rice quality and yield parameters deteriorated significantly [39].

Therefore, many studies have used the traditional breeding and molecular biology methods to develop lodging-resistant varieties of rice, the world's leading food crop [2]. In rice plants, the traits commonly associated with lodging are cellulose and lignin in the cell wall, spike weight, culm diameter, plant height, and strength of the lower and upper internodes [40]. Among them, lignin has become the target of research on the mechanical strength of the stem. Lignin biosynthesis plays an indispensable role in biotic and abiotic stress, especially in plant growth, development, and lodging resistance [41]. The accumulation of lignin in the cell wall enhanced the mechanical strength of the plant stem [42]. Lignin is a structural module composed of cell walls; it is a phenolic polymer, accumulating through the oxidative coupling of monolignols [43,44]. Generally, lignin is transported into the vascular tissues to provide strength to the cell wall [44]. Peng et al. studied the accumulation of lignin, which was significantly positively correlated with the internode breaking strength and stem lodging resistance in winter wheat [45]. The decrease in lignin level is accompanied by a decrease in lodging resistance. It became a new target in breeding to search for genes controlling stem lignin [46]. Lignin acts as a physical barrier against infection and provides mechanical support and strength to the cell wall. In particular, using QTL analysis to localize lodging resistance genes is currently being studied $[1,6,10,16,37]$, but most of them focus on the weight-bearing capacity of rice stems after the heading date or in fully mature stage $[1,16]$. In this study, we investigated the lower stem strength in its fully mature stage, and we observed the lower stem strength during the vegetative growth period to search for the candidate genes related to stem mechanical strength. Therefore, PSLSA and PSLSB were evaluated using QTL analysis. The QTL analysis detected on RM439-RM20318 on chromosome 6 has overlap among three years. RM439-RM20318 on chromosome 6 contained 15 candidate genes related to the pushing strength of the lower stem. Among the candidate genes, Os06g0623200, similar to cinnamoyl-CoA reductase, named OsPSLSq6, which is involved in lignin biosynthesis, can be a target gene.

During lignin biosynthesis, OsPSLSq6, which is similar to Cinnamoyl-CoA reductase, the CCR (Cinnamoyl-CoA reductase) and CAD (cinnamyl alcohol dehydrogenase) enzyme catalyze NADPH-dependent reductions to convert the cinnamic acid-derived metabolites into monolignols. $C C R$ and $C A D$ are present in most plant species and are encoded by various gene families. $C C R$ directs the phenylpropanoid metabolites into the monolignol pathway $[47,48]$. The CCR expression was downregulated by a reduction in lignin content, as demonstrated in several plant species [49]. CCR generally utilizes many distinct hydroxycinnamoyl-CoA substrates, including feruloyl-CoA, 5-hydroxyferuloyl-CoA, sinapoyl$C o A$, and $p$-coumaroyl-CoA, although most $C C R$ isoforms show a kinetic preference for feruloyl-CoA [50]. Moreover, Pan et al. 2014 [48] reported the structural and functional characterization of $C C R$, which catalyze the reductions in monolignol biosynthesis from cinnamic acid, and distinguished them by promoting the activity in the carbon and sulfur bond cleavage (the thioester linkage between the hydroxycinnamoyl moiety and $C o A$ ) and require an additional proton donor for the thiolate leaving group.

Rice and Arabidopsis contain a large family of CCR. These gene families suggest the functional expulsion in the lignin biosynthetic pathway. Kawasaki et al. 2006 [44] studied the lignification function of OsCCR1 in the defense response of transgenic rice which significantly suppresses the OsCCR1 expression through RNA interference, and it still 
occurred at the HR sites induced by incompatible blast fungus. Moreover, CCR enzymes are functionally involved in the synthesis of monolignols, and it also affected the lignin accumulation in Arabidopsis thaliana mutant ( $c a d-d, c a d-c$, and $c c r 1)$, resulting in a decrease in lignin content [51]. In ryegrass, COMT1 and CCR1 genes altered the lignin content and its composition by enhancing the edibility without any negative effects on plant biomass [52]. Similarly, Liang et al. 2006 [53] reported that in A. thaliana mutant, compared to the wild type, the lower lignin content decreased the germination rate of seeds, while in CCR1 mutant, the decreased lignin content resulted in stunted growth and reduced seeds amount [54]. Moreover, the disruption of $C C R$ and $C A D$ led to a lower lignin content in A. thaliana and changed its composition, which results in a lack of lignin in anthers that may inhibit male sterility and plant growth [51].

Recently many studies have approached the lignin biosynthetic pathway and revealed the downregulation of the CCR1 gene, which encodes an enzyme that converts feruloyl-Co $A$ into coniferaldehyde, resulting in the synthesis of $F A-C O A$ and its derivatives [55]. Similarly, Smith et al. 2017 [56] reported the lower lignin content in CCR1 plants and revealed that the decrease in the lignin content had no negative impact on the growth of mutant plants. Moreover, in CCR1 mutant plants, the increase in monolignol ferulate fusion into lignin may provide better substrates as biofuels and higher stover yield. It can also provide a feasible method to increase monolignol ferulate in other crops.

Therefore, we conducted the QTL mapping for the pushing strength of the lower stem in two different stages of rice growth between RM439-RM20318 on chromosome 6; a target gene, OsPSLSq6, which is similar to CCR, was classified according to function. Moreover, the function of $C C R$ in growth and development has been confirmed in several plant species and organs by transgenic methods [57-59]. CCR increased the lignin content and changed the lignin deposition to improve the mechanical strength of the stem to reduce lodging. In this study, the differences in QTL mapping between PSLSA and PSLSB for three consecutive years can be explained by the differences in environmental characteristics [60]. With a scientific basis for rice breeding, OsPSLSq6 can be employed in further studies as a new target for lodging resistance. Finally, the comparison between the gene expression and phenotype through gene introduction to its parental cultivar will be helpful to understand their function after cloning the genes.

\section{Conclusions}

Lodging is one of the unsolved problems in crops. Lignin has become the target of research on the mechanical strength of stem resistance to lodging. In this study, QTL analysis of PSLSA and PSLSB detected on RM439-RM20318 on chromosome 6 has overlap among for three consecutive years. Between RM439 and RM20318 region of chromosome 6, we found 15 candidate genes associated with lodging, in which OsPSLSq6 was selected as the target gene. The results of this study suggest the positive role of OsPSLSq6, which is similar to CCR involved in lignin biosynthesis, which may have a possible role in improving the stem's mechanical strength for lodging resistance. After many QTL analyses, it was concluded that OsPSLSq6 plays an important role in lodging, which are yet to be discovered. The sequences similar to OsPSLSq6 have been found not only in Oryza sativa but also in Zea mays and have an essential role in lignin biosynthesis. Correlation analysis showed that PSLSA and PSLSB have a significantly positive correlation with yield. Although there is still a need to further study OsPSLSq6 and its role in lodging, OsPSLSq6 may be involved in lodging to increase the lignin content, mechanical strength of the stem, and yield. It was also observed that the incorporation of OsPSLSq6 in crop improvement programs is a potential tool to improve the various aspects of crops. 
Supplementary Materials: The following are available online at https:/ /www.mdpi.com/2073-439 5/11/2/334/s1, Table S1: Pushing strength of the lower stem (After 45 days of the heading date), pushing strength of the lower stem (Before heading date) and yield of 120 Cheongcheong/Nagdong double haploid $(\mathrm{CNDH})$ population. Table S2: QTL related to the pushing strength of the lower stem of the CNDH population. Figure S1: Measurement of pushing strength of the lower stem before heading date and after 45 days of heading date (a) pushing strength of the lower stem was measured when the plants were pushed to an angle of $45^{\circ}$ from the vertical direction; (b) measurement of the pushing strength of the lower stem before heading date; (c) measurement of the pushing strength of the lower stem after 45 days of heading date.

Author Contributions: Conceptualization and writing manuscript by D.-D.Z.; Investigation by D.D.Z.; J.H.S.; Writing-Review and editing. D.-D.Z.; G.-S.L.; K.-M.K.; Project supervision by K.-M.K. All authors have read and agreed to the published version of the manuscript.

Funding: This research received no external funding.

Institutional Review Board Statement: Not applicable.

Informed Consent Statement: Not applicable.

Data Availability Statement: Not applicable.

Acknowledgments: This work was supported by a grant from the New Breeding Technologies Development Program (Project No. PJ014793022021), Rural Development Administration, Republic of Korea.

Conflicts of Interest: The authors declare no conflict of interest.

\section{References}

1. Kashiwagi, T.; Ishimaru, K. Identification and functional analysis of a locus for improvement of lodging resistance in rice. Plant Physiol. 2004, 134, 676-683. [CrossRef]

2. Shah, L.; Yahya, M.; Shah, S.M.A.; Nadeem, M.; Ali, A.; Ali, A.; Wang, J.; Riaz, M.W.; Rehman, S.; Wu, W. Improving lodging resistance: Using wheat and rice as classical examples. Int. J. Mol. Sci. 2019, 20, 4211. [CrossRef] [PubMed]

3. Zhang, W.-J.; Li, G.-H.; Yang, Y.-M.; Quan, L.; Zhang, J.; Liu, J.-Y.; Shaohua, W.; She, T.; Ding, Y.-F. Effects of nitrogen application rate and ratio on lodging resistance of super rice with different genotypes. J. Integr. Agric. 2014, 13, 63-72. [CrossRef]

4. Kuai, J.; Yang, Y.; Sun, Y.; Zhou, G.; Zuo, Q.; Wu, J.; Ling, X. Paclobutrazol increases canola seed yield by enhancing lodging and pod shatter resistance in Brassica napus L. Field Crops Res. 2015, 180, 10-20. [CrossRef]

5. Zuo, Q.; Kuai, J.; Zhao, L.; Hu, Z.; Wu, J.; Zhou, G. The effect of sowing depth and soil compaction on the growth and yield of rapeseed in rice straw returning field. Field Crops Res. 2017, 203, 47-54. [CrossRef]

6. Kashiwagi, T. Identification of quantitative trait loci for resistance to bending-type lodging in rice (Oryza sativa L.). Euphytica 2014, 198, 353-367. [CrossRef]

7. Mulsanti, I.W.; Yamamoto, T.; Ueda, T.; Samadi, A.F.; Kamahora, E.; Rumanti, I.A.; Thanh, V.C.; Adachi, S.; Suzuki, S.; Kanekatsu, M. Finding the superior allele of japonica-type for increasing stem lodging resistance in indica rice varieties using chromosome segment substitution lines. Rice 2018, 11, 1-14. [CrossRef] [PubMed]

8. Niu, L.; Feng, S.; Ding, W.; Li, G. Influence of speed and rainfall on large-scale wheat lodging from 2007 to 2014 in China. PLoS ONE 2016, 11, e0157677. [CrossRef]

9. Setter, T.; Laureles, E.; Mazaredo, A. Lodging reduces yield of rice by self-shading and reductions in canopy photosynthesis. Field Crops Res. 1997, 49, 95-106. [CrossRef]

10. Samadi, A.F.; Suzuki, H.; Ueda, T.; Yamamoto, T.; Adachi, S.; Ookawa, T. Identification of quantitative trait loci for breaking and bending types lodging resistance in rice, using recombinant inbred lines derived from Koshihikari and a strong culm variety, Leaf Star. Plant Growth Regul. 2019, 89, 83-98. [CrossRef]

11. Berry, P.; Berry, S. Understanding the genetic control of lodging-associated plant characters in winter wheat (Triticum aestivum L.). Euphytica 2015, 205, 671-689. [CrossRef]

12. Ookawa, T.; Aoba, R.; Yamamoto, T.; Ueda, T.; Takai, T.; Fukuoka, S.; Ando, T.; Adachi, S.; Matsuoka, M.; Ebitani, T. Precise estimation of genomic regions controlling lodging resistance using a set of reciprocal chromosome segment substitution lines in rice. Sci. Rep. 2016, 6, 1-12. [CrossRef] [PubMed]

13. Upadhya, D.; Dhakal, R.; Khadka, K.; Rana, S.; Acharya, P.; Rana, R.; Chaudhary, P. Local knowledge on climate-induced traits in rice for improving crop yield, food security and climate resilience. Int. Agric. Innov. Res. J. 2016, 5, 385-396.

14. Ookawa, T.; Hobo, T.; Yano, M.; Murata, K.; Ando, T.; Miura, H.; Asano, K.; Ochiai, Y.; Ikeda, M.; Nishitani, R. New approach for rice improvement using a pleiotropic QTL gene for lodging resistance and yield. Nat. Commun. 2010, 1, 1-11. [CrossRef]

15. Yadav, S.; Singh, U.M.; Naik, S.M.; Venkateshwarlu, C.; Ramayya, P.J.; Raman, K.A.; Sandhu, N.; Kumar, A. Molecular mapping of QTLs associated with lodging resistance in dry direct-seeded rice (Oryza sativa L.). Front. Plant Sci. 2017, 8, 1431. [CrossRef] 
16. Kashiwagi, T.; Togawa, E.; Hirotsu, N.; Ishimaru, K. Improvement of lodging resistance with QTLs for stem diameter in rice (Oryza sativa L.). Theor. Appl. Genet. 2008, 117, 749-757. [CrossRef]

17. Kong, E.; Liu, D.; Guo, X.; Yang, W.; Sun, J.; Li, X.; Zhan, K.; Cui, D.; Lin, J.; Zhang, A. Anatomical and chemical characteristics associated with lodging resistance in wheat. Crop J. 2013, 1, 43-49. [CrossRef]

18. Kim, T.; Kim, K.; Manigbas, N.L.; Yi, G.; Sohn, J. Identification of quantitative trait loci for resistance to white-backed planthopper (Sogatella furcifera) in rice with Milyang 46 (Cheongcheongbyeo) background. Philipp. J. Crop Sci. 2013, 38, 30-36.

19. Lee, G.-H.; Yun, B.-W.; Kim, K.-M. Analysis of QTLs associated with the rice quality related gene by double haploid populations. Int. J. Genom. 2014, 2014, 781832. [CrossRef]

20. Wang, X.; Chung, I.K.; Kim, H.Y.; Kim, K.-M. Plant development of new ecological model related to yield using QTL analysis. Euphytica 2018, 214, 1-11. [CrossRef]

21. Kim, Y.; Choi, M.; Lee, K.; Baek, M.; Ku, B.; Kang, S.; Park, H.; Kim, B. Growth and yield of rice in levels of nitrogen and water management of reclaimed saline soil in southwestern area. Korean J. Crop Sci./Hanguk Jakmul Hakhoe Chi 2012, 57, $203-208$. [CrossRef]

22. Yoshida, S. Fundamentals of Rice Crop Science; International Rice Research Institute: Los Baños, Philippines, 1981.

23. Lincoln, S.E.; Daly, M.J.; Lander, E.S. Constructing genetic linkage maps with MAPMAKER/EXP Version 3.0: A tutorial and reference manual. Whitehead Inst. Biomed. Res. Tech. Rep. 1993, 3, 6-40.

24. Yun, B.-W.; Kim, M.-G.; Handoyo, T.; Kim, K.-M. Analysis of rice grain quality-associated quantitative trait loci by using genetic mapping. Am. J. Plant Sci. 2014, 2014, 1125. [CrossRef]

25. McCough, S.R.; Doerge, R.W. QTL mapping in rice. Trends Genet. 1995, 11, 482-487. [CrossRef]

26. Zeng, Z.-B. Precision mapping of quantitative trait loci. Genetics 1994, 136, 1457-1468. [CrossRef]

27. Sakai, H.; Lee, S.S.; Tanaka, T.; Numa, H.; Kim, J.; Kawahara, Y.; Wakimoto, H.; Yang, C.-C.; Iwamoto, M.; Abe, T. Rice Annotation Project Database (RAP-DB): An integrative and interactive database for rice genomics. Plant Cell Physiol. 2013, 54, e6. [CrossRef]

28. Sato, Y.; Takehisa, H.; Kamatsuki, K.; Minami, H.; Namiki, N.; Ikawa, H.; Ohyanagi, H.; Sugimoto, K.; Antonio, B.A.; Nagamura, Y. RiceXPro version 3.0: Expanding the informatics resource for rice transcriptome. Nucleic Acids Res. 2013, 41, D1206-D1213. [CrossRef] [PubMed]

29. Pruitt, K.D.; Tatusova, T.; Maglott, D.R. NCBI reference sequences (RefSeq): A curated non-redundant sequence database of genomes, transcripts and proteins. Nucleic Acids Res. 2007, 35, D61-D65. [CrossRef] [PubMed]

30. Hall, T. BioEdit Version 7.0.0. Distributed by the Author. 2004. Available online: www.mbio.ncsu.edu/BioEdit/bioedit.html (accessed on 27 December 2020).

31. Park, J.-R.; Yang, W.-T.; Kim, D.-H.; Kim, K.-M. Identification of a Novel Gene, Osbht, in Response to High Temperature Tolerance at Booting Stage in Rice. Int. J. Mol. Sci. 2020, 21, 5862. [CrossRef] [PubMed]

32. Lu, C.-F.; Shen, L.-S.; Tan, Z.; Xu, Y.; He, P.; Chen, Y.; Zhu, L. Comparative mapping of QTLs for agronomic traits of rice across environments using a doubled haploid population. Theor. Appl. Genet. 1996, 93, 1211-1217. [CrossRef] [PubMed]

33. Hussain, A.; Mun, B.-G.; Imran, Q.M.; Lee, S.-U.; Adamu, T.A.; Shahid, M.; Kim, K.-M.; Yun, B.-W. Nitric oxide mediated transcriptome profiling reveals activation of multiple regulatory pathways in Arabidopsis thaliana. Front. Plant Sci. 2016, 7, 975. [CrossRef] [PubMed]

34. Ebbs, S.D.; Kochian, L.V. Phytoextraction of zinc by oat (Avena sativa), barley (Hordeum vulgare), and Indian mustard (Brassica juncea). Environ. Sci. Technol. 1998, 32, 802-806. [CrossRef]

35. Noor, R.B.M.; Caviness, C. Influence of Induced Lodging on Pod Distribution and Seed Yield in Soybeans 1. Agron. J. 1980, 72, 904-906. [CrossRef]

36. Evans, J.R. Nitrogen and photosynthesis in the flag leaf of wheat (Triticum aestivum L.). Plant Physiol. 1983, 72, 297-302. [CrossRef]

37. Kashiwagi, T.; Sasaki, H.; Ishimaru, K. Factors responsible for decreasing sturdiness of the lower part in lodging of rice (Oryza sativa L.). Plant Prod. Sci. 2005, 8, 166-172. [CrossRef]

38. Weber, C.; Fehr, W. Seed yield losses from lodging and combine harvesting in soybeans 1. Agron. J. 1966, 58, 287-289. [CrossRef]

39. Lang, Y.-Z.; Yang, X.-D.; Wang, M.-E.; Zhu, Q.-S. Effects of lodging at different filling stages on rice yield and grain quality. Rice Sci. 2012, 19, 315-319. [CrossRef]

40. Wang, Y.; Wang, X.; Yang, L.; Li, P.; Zhu, J.; Kazuhiko, K.; Wang, Y. Ozone stress increases lodging risk of rice cultivar Liangyoupeijiu: A FACE study. Shengtai Xuebao/Acta Ecol. Sin. 2011, 31, 6098-6107.

41. Liu, Q.; Luo, L.; Zheng, L. Lignins: Biosynthesis and biological functions in plants. Int. J. Mol. Sci. 2018, 19, 335. [CrossRef]

42. Tripathi, S.C.; Sayre, K.; Kaul, J.; Narang, R. Growth and morphology of spring wheat (Triticum aestivum L.) culms and their association with lodging: Effects of genotypes, N levels and ethephon. Field Crops Res. 2003, 84, 271-290. [CrossRef]

43. Boerjan, W.; Ralph, J.; Baucher, M. Lignin biosynthesis. Ann. Rev. Plant Biol. 2003, 54, 519-546. [CrossRef]

44. Kawasaki, T.; Koita, H.; Nakatsubo, T.; Hasegawa, K.; Wakabayashi, K.; Takahashi, H.; Umemura, K.; Umezawa, T.; Shimamoto, K. Cinnamoyl-CoA reductase, a key enzyme in lignin biosynthesis, is an effector of small GTPase Rac in defense signaling in rice. Proc. Natl. Acad. Sci. USA 2006, 103, 230-235. [CrossRef] [PubMed]

45. Peng, D.; Chen, X.; Yin, Y.; Lu, K.; Yang, W.; Tang, Y.; Wang, Z. Lodging resistance of winter wheat (Triticum aestivum L.): Lignin accumulation and its related enzymes activities due to the application of paclobutrazol or gibberellin acid. Field Crops Res. 2014, 157, 1-7. [CrossRef] 
46. Ookawa, T.; Inoue, K.; Matsuoka, M.; Ebitani, T.; Takarada, T.; Yamamoto, T.; Ueda, T.; Yokoyama, T.; Sugiyama, C.; Nakaba, S. Increased lodging resistance in long-culm, low-lignin gh2 rice for improved feed and bioenergy production. Sci. Rep. 2014, 4, 6567. [CrossRef] [PubMed]

47. Lüderitz, T.; Grisebach, H. Enzymic Synthesis of Lignin Precursors Comparison of Cinnamoyl-CoA Reductase and Cinnamyl Alcohol: NADP+ Dehydrogenase from Spruce (Picea abies L.) and Soybean (Glycine max L.). Eur. J. Biochem. 1981, 119, 115-124. [CrossRef] [PubMed]

48. Pan, H.; Zhou, R.; Louie, G.V.; Mühlemann, J.K.; Bomati, E.K.; Bowman, M.E.; Dudareva, N.; Dixon, R.A.; Noel, J.P.; Wang, X. Structural studies of cinnamoyl-CoA reductase and cinnamyl-alcohol dehydrogenase, key enzymes of monolignol biosynthesis. Plant Cell 2014, 26, 3709-3727. [CrossRef] [PubMed]

49. Wagner, A.; Tobimatsu, Y.; Goeminne, G.; Phillips, L.; Flint, H.; Steward, D.; Torr, K.; Donaldson, L.; Boerjan, W.; Ralph, J. Suppression of CCR impacts metabolite profile and cell wall composition in Pinus radiata tracheary elements. Plant Mol. Biol. 2013, 81, 105-117. [CrossRef]

50. Zhou, R.; Jackson, L.; Shadle, G.; Nakashima, J.; Temple, S.; Chen, F.; Dixon, R.A. Distinct cinnamoyl CoA reductases involved in parallel routes to lignin in Medicago truncatula. Proc. Natl. Acad. Sci. USA 2010, 107, 17803-17808. [CrossRef]

51. Thévenin, J.; Pollet, B.; Letarnec, B.; Saulnier, L.; Gissot, L.; Maia-Grondard, A.; Lapierre, C.; Jouanin, L. The simultaneous repression of CCR and CAD, two enzymes of the lignin biosynthetic pathway, results in sterility and dwarfism in Arabidopsis thaliana. Mol. Plant 2011, 4, 70-82. [CrossRef]

52. Tu, Y.; Rochfort, S.; Liu, Z.; Ran, Y.; Griffith, M.; Badenhorst, P.; Louie, G.V.; Bowman, M.E.; Smith, K.F.; Noel, J.P. Functional analyses of caffeic acid O-methyltransferase and cinnamoyl-CoA-reductase genes from perennial ryegrass (Lolium perenne). Plant Cell 2010, 22, 3357-3373. [CrossRef]

53. Liang, M.; Davis, E.; Gardner, D.; Cai, X.; Wu, Y. Involvement of AtLAC15 in lignin synthesis in seeds and in root elongation of Arabidopsis. Planta 2006, 224, 1185. [CrossRef]

54. Vanholme, R.; Storme, V.; Vanholme, B.; Sundin, L.; Christensen, J.H.; Goeminne, G.; Halpin, C.; Rohde, A.; Morreel, K.; Boerjan, W. A systems biology view of responses to lignin biosynthesis perturbations in Arabidopsis. Plant Cell 2012, 24, 3506-3529. [CrossRef]

55. Derikvand, M.M.; Sierra, J.B.; Ruel, K.; Pollet, B.; Do, C.-T.; Thévenin, J.; Buffard, D.; Jouanin, L.; Lapierre, C. Redirection of the phenylpropanoid pathway to feruloyl malate in Arabidopsis mutants deficient for cinnamoyl-CoA reductase 1. Planta 2008, 227, 943-956. [CrossRef] [PubMed]

56. Smith, R.A.; Cass, C.L.; Mazaheri, M.; Sekhon, R.S.; Heckwolf, M.; Kaeppler, H.; de Leon, N.; Mansfield, S.D.; Kaeppler, S.M.; Sedbrook, J.C. Suppression of CINNAMOYL-CoA REDUCTASE increases the level of monolignol ferulates incorporated into maize lignins. Biotechnol. Biofuels 2017, 10, 109. [CrossRef]

57. Piquemal, J.; Lapierre, C.; Myton, K.; O'connell, A.; Schuch, W.; Grima-Pettenati, J.; Boudet, A.-M. Down-regulation of cinnamoylCoA reductase induces significant changes of lignin profiles in transgenic tobacco plants. Plant J. 1998, 13, 71-83. [CrossRef]

58. Chabannes, M.; Barakate, A.; Lapierre, C.; Marita, J.M.; Ralph, J.; Pean, M.; Danoun, S.; Halpin, C.; Grima-Pettenati, J.; Boudet, A.M. Strong decrease in lignin content without significant alteration of plant development is induced by simultaneous downregulation of cinnamoyl CoA reductase (CCR) and cinnamyl alcohol dehydrogenase (CAD) in tobacco plants. Plant J. 2001, 28, 257-270. [CrossRef]

59. Giordano, A.; Liu, Z.; Panter, S.N.; Dimech, A.M.; Shang, Y.; Wijesinghe, H.; Fulgueras, K.; Ran, Y.; Mouradov, A.; Rochfort, S. Reduced lignin content and altered lignin composition in the warm season forage grass Paspalum dilatatum by down-regulation of a Cinnamoyl CoA reductase gene. Transgenic Res. 2014, 23, 503-517. [CrossRef] [PubMed]

60. Xiao, J.; Li, J.; Yuan, L.; Tanksley, S. Identification of QTLs affecting traits of agronomic importance in a recombinant inbred population derived from a subspecific rice cross. Theor. Appl. Genet. 1996, 92, 230-244. [CrossRef] 